\title{
A Causal Model of Breastfeeding Duration among Working Muslim Mothers in Semarang City, Central Java Province, Indonesia
}

\author{
Mekar Dwi ANGGRAENI ${ }^{1,2}$, Busakorn PUNTHMATHARITH ${ }^{1, *}$ and \\ Wongchan PETPICHETCHIAN ${ }^{1}$
}

\author{
${ }^{1}$ Faculty of Nursing, Prince of Songkla University, Songkhla 90110, Thailand \\ ${ }^{2}$ Department of Nursing, Faculty of Health Sciences, Universitas Jenderal Soedirman, Indonesia
}

('Corresponding author’s e-mail: p.busakorn@gmail.com)

Received: 10 April 2018, Revised: 20 December 2018, Accepted: 30 January 2019

\begin{abstract}
Islam encourages every mother to breastfeed; however, for working mothers, maintaining breastfeeding can be challenging. This study aimed to develop and test a causal model to predict breastfeeding duration in this population. A cross-sectional, predictive study was conducted to test the proposed causal model predicting breastfeeding duration among working Muslim mothers in Semarang City, Central Java Province, Indonesia. Two hundred and forty Muslim mothers participated in the study and self-reported questionnaires were used. Respondents were recruited by using multisite random sampling. Nine questionnaires were used to collect data and a model test using a path analysis was performed to examine the hypothesized relationships. The study results were as follows: 1) initially, the hypothesized model did not fit the data, then the model was modified based on the statistical and theoretical considerations until it could explain the data well, 2) the intention to exclusively breastfeed affected breastfeeding initiation, 3) breastfeeding knowledge and attitude toward breastfeeding affected intention to exclusively breastfeed, 4) breastfeeding knowledge, family support, workplace support, attitude toward breastfeeding, sufficient milk supply, and intention to exclusively breastfeed affected breastfeeding duration, 5) breastfeeding problems affected breastfeeding duration, 6) intention to exclusively breastfeed mediated breastfeeding knowledge and attitude toward breastfeeding on breastfeeding duration and breastfeeding initiation, 7) breastfeeding initiation did not mediate breastfeeding knowledge, family support, and intention to exclusively breastfeed on breastfeeding duration. Health care providers should consider that breastfeeding knowledge, attitude toward breastfeeding, and intention to exclusively breastfeed have high predictive values of exclusive breastfeeding duration among working mothers.
\end{abstract}

Keywords: Causal model, Breastfeeding duration, Working Muslim mothers

\section{Introduction}

These days, social, educational, and cultural changes have led to increased numbers of working women. Currently, women in developing countries tend to work outside the home much more than they did in the last 2 decades [1] and almost $50 \%$ of Indonesian women are now employed [2]. Working outside the home affects the whole life of a woman and one of the factors most affected by maternal working status is child nutrition [3]. Evidence highlights the association between maternal working status and both breastfeeding duration and exclusive breastfeeding (EBF) duration [4]. According to the World Health Organization (WHO) [5], every infant should receive breast milk exclusively from birth up to 6 months and should continue breastfeeding alongside supplementary food until the age of 2 years. 
http://wjst.wu.ac.th

Breastfeeding is one of the norms in Indonesia where almost $96.1 \%$ of infants are breastfed [6]. The percentages of Indonesian mothers who initiate breastfeeding within $1 \mathrm{~h}$ and 1 day after delivery are 49.3 and $66.3 \%$, respectively [6]. The mean of breastfeeding duration is quite long (20.5 months) [6]. However, EBF is uncommon among Indonesian mothers, with only $48.6 \%$ of them exclusively breastfeeding their infants up to the age of 6 months [7]. The mean of EBF duration in Indonesia is 3 months [6] and there are several factors which influence this.

Religious and cultural beliefs may influence health behaviors among individuals, and so religious beliefs may affect breastfeeding duration among Muslim mothers. Islam encourages Muslim mothers to breastfeed up to 2 years since delivery [8]; however, EBF is rarely practiced by Muslim mothers [9]. Indonesian Muslims believe that infants should be provided with a chewed date or a little honey in the soft palates just after birth [10]. This too may affect exclusive breastfeeding practice among Muslim mothers. In addition, the Javanese community has specific beliefs related to breastfeeding, such as providing supplementary food to their infants before the age of 6 months [11]. There has, as yet, been no population-based study regarding EBF duration among working Muslim mothers in Central Java Province, Indonesia.

The evidence shows that several factors correlate or predict breastfeeding duration [12-15]. This study investigated 9 modifiable variables which could be managed and modified by a nurse or mother. The selected variables were supported by the theory of planned behavior and empirical evidence. Four of the predictive factors were selected based on the theory of planned behavior. These were: Breastfeeding knowledge [16], attitude toward breastfeeding [14], intention to exclusively breastfeed [17], and breastfeeding duration. The other 5 variables were selected based on a literature review and were: Family support [13], workplace support [9], breastfeeding problems [18], sufficient milk supply [19] and breastfeeding initiation [20].

Breastfeeding knowledge influences breastfeeding initiation, intention to exclusively breastfeed, and breastfeeding duration among working mothers. A study of Indonesian mothers reveals that those with a lot of breastfeeding knowledge are more likely to initiate breastfeeding within the 1st hour of delivery [21]. Similar to other breastfeeding mothers, lactating working mothers in Indonesia need family support to continue breastfeeding their infants exclusively after returning home from work [15]. A study in Bangladesh found a significant correlation between family support and EBF duration [13]. Working Indonesian mothers who receive breastfeeding support from their husband exclusively breastfeed for longer than mothers who do not receive support from the husbands [15]. Support from family members also positively correlates with breastfeeding intention among Syrian and Lebanese mothers [22]. Workplace breastfeeding support is a significant predictor of breastfeeding duration among working mothers in Malaysia [12]. One employer supports working mothers to breastfeed by providing break times and breast milk pumping facilities in the workplace. Evidence shows that attitude toward breastfeeding is a predictor of breastfeeding intention. The significant factor influencing EBF intention among Bangladeshi mothers is an attitude toward EBF [14]. Another Indonesian study reports that attitude toward EBF significantly predicts EBF duration [23]. Breastfeeding is influenced by religious beliefs and philosophy. One literature review shows that mothers' religiosity influences breastfeeding duration and that Singaporean Muslim mothers are more likely to breastfeed compared to mothers of other religions [24]. Breastfeeding problems in the postpartum period influence mothers' intention to give supplementary food before the infant is 6 months old [25].

Breastfeeding duration is also affected by perceived sufficient milk supply. Mothers who perceive the quantity of milk supply sufficient to meet their infants' needs are less likely to provide supplementary food [26]. In contrast, perceived insufficient milk supply is a predictor for short breastfeeding duration [20] and is the major reason that Indonesian mothers give supplementary food to their infants before the age of 6 months [27]. Evidence shows that the intention to EBF significantly influences EBF duration among Turkish mothers [26]. There is a significant correlation between breastfeeding initiation and breastfeeding duration [20].

Previous studies have examined the correlation and prediction among variables; however, these studies were fragmented (13), used small sample sizes (15), studied non-working mothers (14), studied non-Muslim populations (20), and did not use a research framework (16). Little is known regarding 
http://wjst.wu.ac.th

intervention to enhance EBF among working Muslim mothers in either the English or Indonesian language publications. The causal model provides important evidence regarding the influencing factors and the relationships among the influencing factors. This study examined the following research questions: Does the hypothesis model fit the data? And what are the factors that influence exclusive breastfeeding duration among Indonesian working Muslim mothers? The purpose of this study was to examine the causal relationships among the predictors of breastfeeding duration.

\section{Materials and methods}

\section{Setting and sample}

The population in this study was lactating working Muslim mothers in Semarang, Central Java Province, Indonesia, with infants aged from 6 months to 1 year.

The inclusion criteria for mothers were as follows: being married, being over 20-years-old, having no history of complications after delivery (e.g., postpartum hemorrhage or convulsion), and working outside the home for at least $8 \mathrm{~h} / \mathrm{d}$. The inclusion criteria for infants were: Being healthy, having gone full-term, being a singleton, and having weighed more than $2,500 \mathrm{~g}$ at birth.

The exclusion criteria for mothers were: Drug abuse, suffering a disease that may interfere with breastfeeding (e.g., HIV/AIDS, herpes simplex with lesion on breast, untreated active tuberculosis, maternal syphilis, and diabetes), 3) on-going treatment (e.g., radioactive therapy, chemotherapy, psychosis therapy, and anti-convulsion therapy), and a history of inverted nipples, hypoplastic breast, or breast surgery that may interfere with breastfeeding. The exclusion criteria for infants consisted of: Serious illness or complications that may interfere with the latch on or breastfeeding processes (e.g., cleft lip, cleft palate, and esophageal atresia). According to Nunnally and Bernstein [28], a causal model study needs 30 subjects for each independent variable. This study had 8 independent variables, giving a sample size of 240 mothers.

The researcher used a multisite random sampling to select the sample. The researcher selected the sample in Semarang City because it is the capital city in Central Java Province, located in an urban area, and most of the mothers in this location work outside the home. There are 16 districts in Semarang City. The multisite random sampling started by randomly selecting 4 districts in Semarang City, namely, Ngaliyan, Mijen, Banyumanik, and Semarang Barat. The researcher randomly selected 1 or 2 Primary Health Care (PHC) centers in each district based on the number of PHC centers in each district. The selected PHC centers were: Ngaliyan, Mijen, Srondol, Ngesrep, Manyaran, Ngemplak, and Kagok. The Kagok PHC center was used to test the reliability of the research instruments while the other 6 PHC centers were used to collect research data.

\section{Measures}

Ten questionnaires or scales were used to measure the variables. The 6 modified scales were examined for content validity, language, and cultural suitability by a panel of 5 experts consisting of 2 faculty members from the Obstetric and Gynecological Department of the Faculty of Nursing at Prince of Songkla University, a pediatrician with expertise in breastfeeding in Thailand from the Faculty of Medicine, Prince of Songkla University and 2 other faculty members from the Maternity Nursing Department of the University of Indonesia with expertise in breastfeeding in Indonesia. The reliabilities of the scales were performed with 20 lactating working Muslim mothers. All details of content validity indices (CVI) and reliabilities were mentioned in each scale.

The questionnaires or scales were developed in the English language and a back translation was performed based on the works of Hilton and Skrutkowski [29]. The research instrument translation process in this study was started by translating the English language version questionnaire or scale into a Bahasa Indonesian version. Next, the questionnaires or scales were translated back from Bahasa Indonesian into English. Both of these processes were carried out by 3 bilingual nurses with masters' degrees from countries where English is the main language. In the 3rd step of the back-translation process, a native English speaker compared and examined the original and back-translated questionnaires 
http://wjst.wu.ac.th

or scales. The native speaker gave recommendations to change some words in the back-translation to match the original questionnaire or scale. The details of each questionnaire or scale are as follows.

1. The personal characteristics questionnaire was developed by the researcher based on a literature review of factors that influence EBF duration. This questionnaire consisted of 14 items relating to the personal demographics of mother, husband, and infant.

2. The modified Malay-version of the breastfeeding knowledge questionnaire was developed by Ismail and Sulaiman [30]. The 47 items and 10 dimensions of breastfeeding knowledge were as follows: Advantages to baby (6 items), advantages to mother (6 items), colostrum (4 items), effective feeding (3 items), breast milk expression ( 8 items), duration of feeding (4 items), complementary feeding ( 2 items), problems with breastfeeding (5 items), breast engorgement (2 items), and practical aspects of breastfeeding ( 7 items). For this study, the researcher modified the questionnaire based on the experts' suggestions and a literature review in order to more accurately represent the concept of breastfeeding knowledge among working mothers in Javanese culture. The total number of items in this questionnaire was 49 and each item had categorical responses of correct and incorrect. A correct response was given a score of 1 , while a wrong response was given a score of 0 . Therefore, it was possible for participants to score between 0 and 49, with a higher score indicating higher breastfeeding knowledge. In this study, the CVI of the questionnaire was 0.96 and the Kuder-Richardson 20 reliability was 0.82 .

3. The modified family support questionnaire was developed by Biswas [13], based on the concept of social support proposed by House [31] to measure family support of breastfeeding mothers. There were 20 items with 4 dimensions. The dimensions were as follows: Emotional (5 items), instrumental (5 items), informational (5 items), and appraisal support (5 items). This instrument was a 5-item Likert scale, and responses ranged from 1 (never) to 5 (always). For this study, the researcher added 1 item in dimension 1 (emotional support) and another item in dimension 2 (instrumental support), based on a literature review regarding family support to lactating working mothers. This questionnaire had 22 items of positive statements. The total score and each dimension of the questionnaire can be obtained by adding the total score of all items or each dimension and dividing by the number of the total items or total of each dimension's items. The mean score ranged from 1 to 5 , with a higher score indicating a greater perception of family support. In this study, the CVI of the questionnaire was 0.95 and the Cronbach's Alpha coefficient was 0.94 .

4. The modified workplace breastfeeding support scale was developed by Bai, Peng, and Fly [17] in the United States and was based on the findings of a literature review. The 12 items and 4 dimensions were as follows: Technical ( 3 items), environmental (3 items), facility (3 items), and peer support (3 items). For this study, the researcher modified 2 items to make the scale fit Indonesian and Muslim contexts. All items in this questionnaire were positive statements and used a 7-points Likert scale. Each dimension's score on this scale can be obtained by adding the total score of each dimension and dividing it by the total number of each dimension's items. The mean score ranged from 1 to 7 with a higher score indicating a greater perception of workplace breastfeeding support. In this study, the CVI of the scale was 0.85 and the Cronbach's Alpha coefficient was 0.87 .

5. The original breastfeeding attitude questionnaire was developed by Khatun [14] to measure the breastfeeding attitude of breastfeeding mothers. It consisted of 2 subscales: Breastfeeding beliefs (23 items) and the outcome evaluation of breastfeeding beliefs (23 items). This questionnaire used a 5-points Likert scale for all items ranging from 5 (strongly agree) to 1 (strongly disagree). For this study, the researcher made minor modifications in 12 items to make them fit Javanese cultural beliefs. The researcher added 2 items to the breastfeeding beliefs subscale and 2 items to the outcome evaluation subscale based on the religious beliefs of Muslim mothers. Thus, the modified breastfeeding attitude questionnaire consisted of 50 items and 2 subscales: Breastfeeding beliefs (25 items) and the outcome evaluation of breastfeeding beliefs ( 25 items). The total breastfeeding attitude scores ranged from 625 to 15,625 and the mean of breastfeeding attitude scores ranged from 12.5 to 312.5. A higher score indicated a more positive mother's attitude toward breastfeeding. In this study, the CVI of the questionnaire was 0.95 and the Cronbach's Alpha coefficient was 0.95 .

6. The breastfeeding experience scale was developed by Wambach [32] to measure perceived breastfeeding problems. This tool had 2 parts, with the 1st part consisting of 17-rating scale items and the 
2nd part being 1 open-ended item. A 5-points rating scale for each item ranged from 1 (not at all) to 5 (unbearable). The total scores can be obtained by adding all the responses together. Mean scores were calculated by dividing the total scores by the total breastfeeding problems. A higher score indicated greater perception of breastfeeding problems. In this study, the Cronbach's Alpha coefficient of the scale was 0.89 .

7. The 9-items H \& H lactation scale was modified from the original H \& H Lactation Scale [33] and tested for psychometric properties by Punthmatharith and Singh [34] in Thailand with the permission of Hill and Humenick. The 9-items H \& H Lactation Scale consisted of 9 items and 3 dimensions: Maternal confidence in/commitment to breastfeeding ( 3 items), perceived infant breastfeeding satiety (3 items), and maternal-infant breastfeeding satisfaction (3 items). It was a self-report instrument where all items were anchored with a 7-points Likert scale ranging from 1 (strongly disagree) to 7 (strongly agree). The researcher started score calculation by reversing the negatively scored items, then the ratings of all of the items were entered and the last counting the average mean of individual item scores and the average mean of each subscale (composite scores). Higher scores reflected greater levels of mothers' confidence in/commitment to breastfeeding, perceived infant satiety, and mother-infant breastfeeding satisfaction. In this study, the Cronbach's Alpha coefficient of the scale was 0.85 .

8. The intention to exclusively breastfeed scale was developed by Khatun, Punthmatharith, and Orapiriyakul [14] based on the theory of reasoned action [35] and a literature review. It is a 0 to 10-points numeric rating scale containing the endpoints of "I should not exclusively breastfeed my baby for at least 6 months postpartum" (0) and "I should exclusively breastfeed my baby for at least 6 months postpartum" (10). The midpoint (5) of the scale represents unsurety in the mother. A higher score represented a stronger intention in the 3rd trimester of pregnancy to perform EBF. In this study, the time interval for performing a test-retest reliability was a day and the Pearson correlation reliability of the scale was 0.99 .

9. The breastfeeding initiation scale was developed by the researcher based on a literature review. Breastfeeding initiation should be carried out within the $1^{\text {st }}$ hour of delivery. Breastfeeding initiation information was gleaned from 1 question: "How many $\mathrm{min} / \mathrm{h}$ after delivery did you start breastfeeding the infant for the $1^{\text {st }}$ time?" The number of $\mathrm{min} / \mathrm{h}$ indicated the working mother's initial breastfeeding. The sooner breastfeeding is initiated, the better. In this study, the time interval for performing a test-retest reliability was a day. The CVI of the scale was 1.0 and the reliability testing by Pearson correlation was 1.0 .

10. The breastfeeding duration scale was developed by the researcher based on a literature review. As suggested by WHO [36], the EBF duration was 6 months. During this time, the infant only feeds on breast milk. The EBF duration data was collected using one question "For how many d/m did you exclusively provide breast milk to the infant?" This number indicated the working mother's breastfeeding duration. A longer breastfeeding duration is considered better. In this study, the time interval for performing a test-retest reliability was a day. The CVI of the scale was 1.0 and the reliability testing by Pearson correlation was 0.99 .

\section{Data collection}

The 1 st phase of the data collection process was preparation and the $2^{\text {nd }}$ phase was data collection. During phase 1, the researcher prepared everything that was needed for data collection. The researcher received an approval letter from the ethics committee of the Faculty of Nursing at Prince of Songkla University and received a permission letter to conduct a reliability test and to collect the research data. Then, the researcher recruited 4 research assistants (RAs) to help collect data. The RAs were nurses with bachelors' degrees in nursing science. The researcher explained the research objectives, the inclusion and exclusion criteria, the recruiting process for potential mothers, the data collection procedure, the research ethics, and the research instruments to the RAs.

Phase 2 began by collecting data from working mothers who had given birth $6-12$ months earlier. Then, the researcher and RAs approached potential mothers to ask for their willingness to join the study. The researcher and RAs introduced themselves and explained the study to the mothers, explained the rights and responsibilities of subjects, and the confidentiality principle. After mothers understood the study, the researcher or RAs asked for mothers' willingness to participate in this study. When the eligible 
http://wjst.wu.ac.th

mothers agreed to participate in the study, they signed informed consent forms. The researcher and RAs explained the questionnaires and provided the opportunity for the mothers to ask questions. The researcher and RAs asked the mothers to fill in all questionnaires completely and stayed with the mothers until they had answered all questions and returned the questionnaires. The researcher and RAs then assessed the completeness and correctness of the questionnaires in the mothers' company. The time required to complete the questionnaires was approximately 120 to $180 \mathrm{~min}$.

\section{Ethical considerations}

To ensure the protection of human rights of the subjects in this study, the researcher asked for approval from the Ethics Committee of the Faculty of Nursing, Prince of Songkla University, Thailand. After approval was obtained, the researcher asked for permission to contact the respondents through the Central Java Province Ministry of Health. Permission was agreed by letter from the Central Java Province Ministry of Health, number 071/5708. All of the respondents' data was kept confidentially by the researcher and was only shared with those associated with the study. The researcher used code during data collection, data analysis, result reports, and publication. Moreover, the respondents had the right to withdraw from the study at any time without any negative consequences, whilst continuing to receive regular health care. The researcher and research assistants managed any potential risk-factors experienced by mothers during data collection, allowing mothers to go to the toilet, breastfeed their infants or to carry out other necessary activities before filling out the questionnaires. The researcher and research assistants also took care of the infants while the mothers were completing the questionnaires.

\section{Data analysis}

The sample characteristics and variables distribution were analyzed using descriptive statistics. Continuous data were summarized as either mean or median, depending on whether the data were normally distributed or not. Categorical data were presented as frequencies and percentages. A path analysis was used to test a causal model of breastfeeding duration among working Muslim mothers.

\section{Results and discussion}

\section{Sample characteristics}

Two hundred and 40 mothers were included in the study. Their ages ranged between 22 and 42 years with a mean age of 30.93 years $(S D=4.16)$. For parity, $40 \%$ of mothers had 2 children and $36.3 \%$ had 1 child. The majority of mothers $(88.4 \%)$ lived with their husbands. Half had completed a bachelor's degree and a quarter of the mothers $(25.8 \%$ ) were teachers. $44 \%$ of mothers had a monthly income of more than 3,400,000 Rupiah (14,000 Rupiah =1 USD). The majority (89.6\%) perceived their incomes as adequate. There were more nuclear families $(57.1 \%)$ than extended families $(42.9 \%)$ and most of the relatives who lived with the mother were parents $(51.9 \%)$. Mothers received most breastfeeding information from three sources: Midwives (63.8 \%), family members $(51.2 \%)$, and friends $(37.9 \%)$. The infants' ages ranged from 185 to $360 \mathrm{~d}$ with a median age of $285 \mathrm{~d}$ (IQR: 49.38). The genders of the infants were nearly equal at $51.7 \%$ for males and $48.3 \%$ for females. More than half of the infants $(61.6$ $\%$ ) were delivered normally. Approximately 3-quarters of the mothers $(74.1 \%)$ gave birth in hospital. 
Table 1 The Direct, Indirect, and Total Effects of the Modified Model.

\begin{tabular}{cccc}
\hline \multicolumn{1}{c}{ Paths } & Direct effects & Indirect effects & Total effects \\
\hline $\mathrm{BK} \rightarrow \mathrm{BI}$ & -0.08 & $-0.10^{* *}$ & $-0.18^{*}$ \\
$\mathrm{BK} \rightarrow \mathrm{IEB}$ & $0.43^{* * *}$ & - & $0.43^{* * *}$ \\
$\mathrm{BK} \rightarrow \mathrm{BD}$ & $0.18^{* * *}$ & $0.10^{* * *}$ & $0.28^{* * *}$ \\
$\mathrm{FS} \rightarrow \mathrm{BI}$ & -0.06 & - & -0.06 \\
$\mathrm{FS} \rightarrow \mathrm{BD}$ & $0.13^{* *}$ & - & $0.13^{* *}$ \\
$\mathrm{WS} \rightarrow \mathrm{BD}$ & $0.08^{*}$ & - & $0.08^{*}$ \\
$\mathrm{ATB} \rightarrow \mathrm{IEB}$ & $0.22^{* * *}$ & - & $0.22^{* *}$ \\
$\mathrm{ATB} \rightarrow \mathrm{BD}$ & $0.41^{* * *}$ & $0.05^{* *}$ & $0.46^{* * *}$ \\
$\mathrm{BI} \rightarrow \mathrm{BD}$ & $-0.08^{*}$ & - & $-0.08^{*}$ \\
$\mathrm{IEB} \rightarrow \mathrm{BI}$ & $-0.22^{* *}$ & - & $-0.22^{* *}$ \\
$\mathrm{IEB} \rightarrow \mathrm{BD}$ & $0.21^{* * *}$ & 0.02 & $0.23^{* * *}$ \\
$\mathrm{BP} \rightarrow \mathrm{BD}$ & $-0.12^{* *}$ & - & $-0.12^{* *}$ \\
$\mathrm{IMS} \rightarrow \mathrm{BD}$ & $0.10^{* * *}$ & - & $0.10^{* *}$
\end{tabular}

Note: $\mathrm{BK}=$ Breastfeeding knowledge, FS $=$ Family support, WS $=$ Workplace support, ATB = Attitude toward breastfeeding, BP = Breastfeeding problems, SMS = Sufficient milk supply, BI = Breastfeeding initiation, IEB = Intention to exclusive breastfeeding, $\mathrm{BD}=$ Breastfeeding duration.

\section{A causal model of breastfeeding duration}

Before testing the path analysis, the researcher examined the correlation of independent variables with dependent variables. All dependent variables correlated with the independent variables $(r=-0.35$ to -0.71). The researcher examined the path analysis assumptions all assumptions were met. The researcher evaluated the hypothesized model using the path analysis and results revealed that the hypothesized model did not fit the data. Based on the modification indices and an empirical evidence consideration, the researcher modified the hypothesized model. The path which had the lowest path coefficient value was dropped (family support of intention to exclusively breastfeed). The results of the modified model test showed that there were 2 non-significant paths out of 13 paths. The final model revealed the best fit with the data (Table 1). The Chi-square test was $16.59(p=0.035)$, relative chi-square $(2.07)$ was less than 3 , NFI (0.99) was more than 0.95, NNFI (0.96) was more than 0.90, GFI (0.98) was more than 0.90, AGFI (0.91) was more than 0.90, CFI (0.99) was more than 0.95, RMSEA $(0.02,0.11)$ met the criteria, and SRMR (0.04) was less than 0.08 or 0.05 . Thus, further interpretation of the results was performed based on the modified model test results.

The overall research hypotheses were partially supported. The modified model test results revealed that all values fit the criteria and $R^{2}=0.75$ (Figure 1). The modified path analysis results showed that breastfeeding knowledge, family support, workplace support, attitude toward breastfeeding, sufficient milk supply, and intention to exclusively breastfeed affected breastfeeding duration directly and positively $(\beta=0.26, p<0.001 ; \beta=0.13, p<0.001 ; \beta=0.07, p<0.05 ; \beta=0.49, p<0.001 ; \beta=0.11, p<$ $0.01 ; \beta=0.23, p<0.001$, respectively). In contrast, breastfeeding problems affected breastfeeding duration directly and negatively $(\beta=-0.11, p<0.01)$ and breastfeeding initiation did not have a direct significant effect on breastfeeding duration $(\beta=-0.06, p>0.05)$. Family support did not significantly affect breastfeeding initiation directly $(\beta=-0.06, \mathrm{p}>0.05)$. Breastfeeding knowledge and intention to exclusively breastfeed had a direct and negative effect on breastfeeding initiation $(\beta=-0.17, p<0.05 ; \beta=$ $-0.22, p<0.01)$. Breastfeeding knowledge and attitude toward breastfeeding affected intention to exclusively breastfeed directly and positively $(\beta=0.42 ; \beta=0.22$, all $p<0.001$, respectively). Breastfeeding knowledge, family support, and intention to exclusively breastfeed did not have an indirect significant effect on breastfeeding duration through breastfeeding initiation $(\beta=-0.01, p>0.05 ; \beta=0.00$, $p>0.05 ; \quad \beta=0.01, p>0.05$, respectively). Breastfeeding knowledge and attitude toward breastfeeding 
http://wjst.wu.ac.th

affected breastfeeding initiation indirectly and negatively through intention to exclusively breastfeed $(\beta=$ $-0.10, p<0.01 ; \beta=-0.01, p<0.01)$. Breastfeeding knowledge and attitude toward breastfeeding affected breastfeeding duration indirectly and positively through intention to exclusively breastfeed $(\beta=0.10, p<$ $0.001 ; \beta=0.05, p<0.01)$.

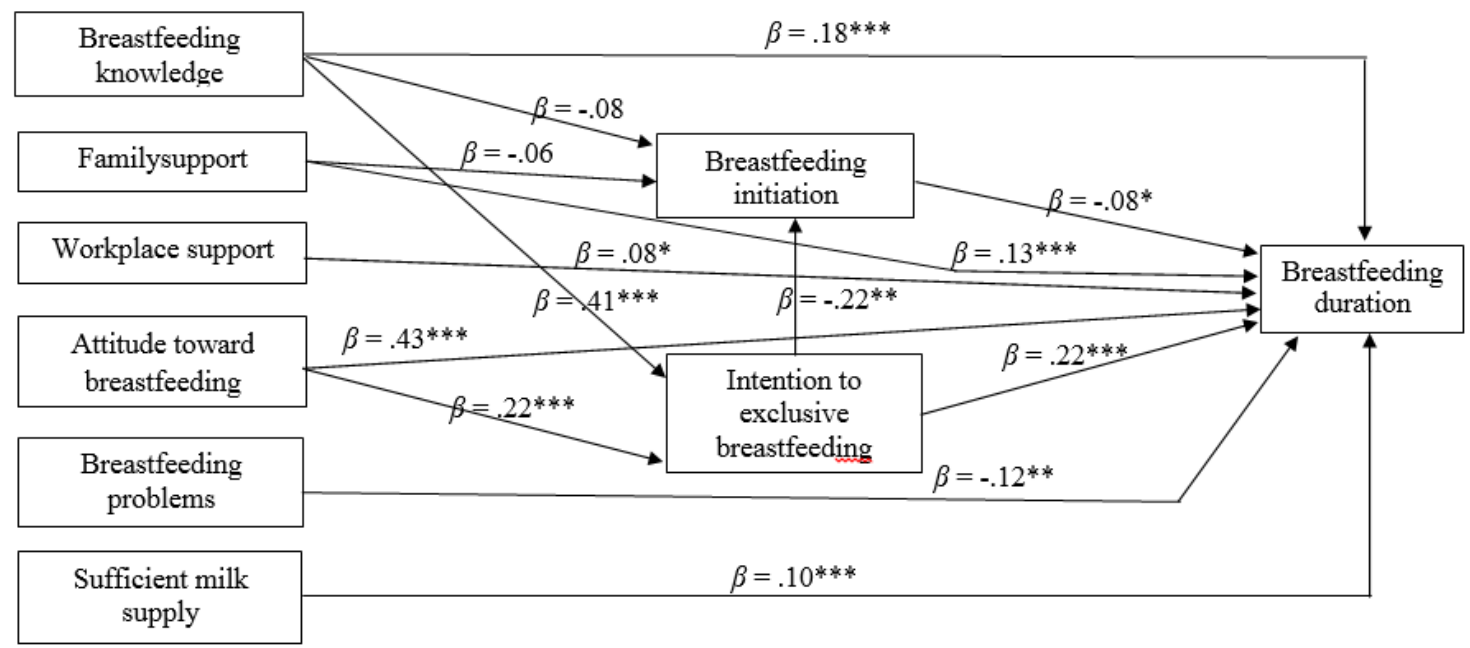

Figure 1 A causal model of breastfeeding duration among Muslim working mothers in Central Java Province, Indonesia

Note: Model fit indices: $\chi^{2}(8, n=240)=14.41, p=0.072 ; \chi^{2} / d f=1.80 ;$ NFI $=0.99 ;$ NNFI $=0.97$; $\mathrm{GFI}=0.99 ; \mathrm{AGFI}=0.93 ; \mathrm{RSMEA}=0.00 ; 0.11 ; \mathrm{SRMR}=0.035$.

\section{Discussion}

The hypothesized model test results partially met the goodness of fit criteria. It was somewhat surprising that family support did not predict intention to exclusively breastfeed. Some factors may contribute to this. Firstly, the majority of respondents in this study had a nuclear family, meaning they may lack family support if their husband was working outside the home. In some cases, husbands were working in other cities and could not give direct support to the breastfeeding mothers. Secondly, half of the subjects were multiparous and of an older age with prior knowledge of breastfeeding. This may have influenced the respondents' intentions to breastfeed. Thirdly, the majority of mothers in this study had been educated to a high level and this may have facilitated them to seek health information for themselves and to be willing to learn from health care providers, which would have given them a good knowledge base and possibly made them more likely to breastfeed. High breastfeeding knowledge and education levels predicted intention of breastfeeding among low-income mothers [37]. These results are in line with Remple, Remple, \& Moore study [38] which found that fathers' support did not increase mothers' intention to breastfeed for longer.

The final model test results met all of the goodness of fit criteria. It was the best fit model compared to the hypothesized model. There were 11 significant paths and 2 non-significant paths. Another study by Duckett et al. [39] also had 2 non-significant paths (i.e., the path from subjective norm to attitude toward breastfeeding in the employed less group, and the path from breastfeeding knowledge to attitude toward bottle feeding in the homemaker group). The modified model test results showed that intention to exclusively breastfeed mediated breastfeeding knowledge and attitude toward breastfeeding on breastfeeding duration. The results in this study were congruent with the theory of planned behavior [35] which states that intention mediates knowledge and attitude on a specific behavior. Previous study results also confirm that intention to breastfeed mediates attitude toward breastfeeding on breastfeeding duration 
[40]. The higher intention and longer duration of exclusive breastfeeding in this study might be related to the prior breastfeeding experience, higher education levels, and older mothers, which may have resulted in more breastfeeding knowledge and a positive attitude toward exclusive breastfeeding. Previous study results have shown that multiparity [41], higher education levels, older mothers, and higher incomes affect breastfeeding knowledge and attitude toward exclusive breastfeeding [42]. Higher knowledge and a more positive attitude affect breastfeeding intention [43]. The findings from previous studies support this study's findings.

Fathers' support during the delivery process had a positive effect on breastfeeding initiation [44], while family support did not significantly affect breastfeeding initiation. A possible reason for this is that the majority of mothers in this study gave birth in a hospital and stayed in the delivery room for up to $2 \mathrm{~h}$ after giving birth without their family member beside them. Breastfeeding initiation should be performed within the 1 st hour of delivery; therefore, health care providers who work in delivery rooms play a more important role in breastfeeding initiation than family members. Family members were generally not allowed to stay in the delivery room so, were unable help mothers initiate breastfeeding within the 1st hour of delivery. Some family members in this study were permitted to stay with mothers in the delivery room, but in these situations, the health care providers did not facilitate breastfeeding initiation and the family member could not make the breastfeeding initiation decision by themselves. In addition, some hospitals do not have a breastfeeding initiation policy; so health care providers do not initiate breastfeeding within the 1st hour of an infant's birth [45]. A study in Indonesia found that the health care providers' attitudes toward breastfeeding initiation had a more significant effect on breastfeeding initiation practice than family support did [46]. Some previous studies by Nugraheni [47] and Nastiti [48] in Indonesia have found that family support does not have a significant effect on breastfeeding initiation.

Attitude toward breastfeeding had the highest effect on breastfeeding duration in this study. A possible explanation is that this study was conducted within the Muslim population. Muslim mothers have strong beliefs about breastfeeding their infants in order to fulfill religious obligations [8]. Islam encourages Muslim mothers to breastfeed their infants up to the age of 2 years and this is stated clearly in the Noble Quran. According to Kamoun and Spatz [49], Islamic traditions affect breastfeeding beliefs and practice among Muslim populations and Muslim mothers tend to have a positive attitude toward breastfeeding. The previous study also showed that mothers who were currently breastfeeding had a more positive attitude compared to non-breastfeeding mothers [50] and that Muslim mothers in Singapore were more likely to breastfeed than non-Muslims. This may be due to the positive beliefs around breastfeeding that exist within this community [24].

Breastfeeding knowledge was the $2^{\text {nd }}$ most significant factor affecting breastfeeding duration in this study. Mothers with higher level of education may have searched for breastfeeding information by themselves. Currently, postpartum Javanese mothers tend to seek breastfeeding information on the internet. This has been found to increase breastfeeding knowledge and affect breastfeeding beliefs in Javanese mothers [11]. In addition, the majority of respondents had adequate incomes which may have facilitated them to seek breastfeeding knowledge by participating in seminars, buying books, joining lactating mothers' groups on social media, or consulting lactation consultants. Previous study results reveal that higher breastfeeding knowledge produces longer breastfeeding duration in Indonesian mothers [15].

The results support the theory of planned behavior which propose that intention affects human behavior. The mothers' intention to breastfeed positively influenced exclusive breastfeeding duration [51]. Stronger intention to breastfeed produces a longer exclusive breastfeeding duration [17]. All respondents in this study were married and multiparous. Previous studies have revealed that married and multiparous mothers have higher intention to breastfeed exclusively [52] and that mothers who have higher intention to breastfeed exclusively tend to breastfeed for longer [53].

All study respondents were full-time working mothers. After finishing maternity leave, full-time working mothers stay in the workplace for at least $8 \mathrm{~h} / \mathrm{d}$. This study had a low-magnitude path between support at the workplace and support on breastfeeding duration. Possible reasons for this are that the workplace provided some support to lactating working mothers such as granting maternity leave, a flexible work schedule, and breast milk pumping break times. However, there are no convenient facilities 
to breastfeed, pump breast milk, store breast milk, or offer childcare at most places of work, and there tends to be a lack of support from co-workers and supervisors. Furthermore, most mothers work out of town. Previous study results confirm that many factors affect breastfeeding duration among working mothers. These include: The availability of a lactation room, sufficient break times [54], effective balancing of work duties with breast pumping [55], child care facilities, breast pump and breast milk storage facilities, job flexibility, a breastfeeding mother-friendly workplace [56], childcare, long maternity leave, short working hours [57], the social and occupational characteristics of mothers [58], a low workload, use breast pumping break, lactation room, encouragement from colleagues and supervisors to use breast pumping breaks [59], co-worker support, organization support, manager support, and consideration and pumping facilities affected breastfeeding duration among working mothers [60].

Family support had a low effect on breastfeeding duration in this study. A possible explanation is that the majority of infants in the study were cared for by a domestic helper (nanny) and this phenomenon was not asked about in the family support questionnaire. This may have affected the respondents' answers about family support regarding their breastfeeding process. The nanny plays an important role in exclusive breastfeeding practice because she is the person responsible for giving expressed breast milk to an infant while the mother is at work. Some nannies complained about the difficulty of giving expressed breast milk to infants. They often gave up and asked for formula feed to be provided using a bottle. Pacifier use and mothers returning to work negatively affected breastfeeding duration [61]. In some cases, exclusive breastfeeding cases in this study were successful because the nannies supported it and provided the expressed breast milk using a spoon or glass. A study among working mothers in Hong Kong by Dodgson's [40] found that when infants are cared for by a nanny or older family member while the mother is working, the decision about breastfeeding duration is not in the mother's control. Previous studies have also found that family support [62] is significantly related to breastfeeding duration.

Breastfeeding problems were experienced by almost all breastfeeding mothers, with around $80 \%$ of participants experiencing problems [63]. Mothers who perceived fewer breastfeeding problems had more intention to breastfeed [37] and longer breastfeeding duration [64]. Working mothers experience more breastfeeding problems comparing to stay-at-home mothers. They have to keep a balance between being a good mom and a good employee [65]. A working mother has to complete similar job tasks to her colleagues and must adhere to a strict job schedule which may affect breast pumping schedule activities. Breast pumping may cause discomfort and pain and mothers may worry about breast milk count, inferred nature breastfeeding process. Mothers may become frustrated [66], suffer breast engorgement or swollen, hard, cracked nipples, mastitis, breast abscesses, reduced breast milk supply, sickness, or fever [67]. Both the maternal perception of insufficient milk and a lack of breast milk significantly affects infant weaning before the age of 6 months in developing countries $[33,68,69]$. Stress may inhibit the breast milk ejection reflex and cause breast engorgement [70]. Working mothers have little time to have physical interaction with their infants and this may affect breast milk production and breastfeeding duration Dodgson [40]. Furthermore, the majority of Javanese breastfeeding mothers look for information on the internet, but this information is inconsistent, incomplete, and not always evidence-informed [71]. This picture is congruent with previous study results in Thai mothers [53], Mauritius mothers [72], first time mothers [73], and American mothers [74].

In this study, breastfeeding initiation had a non-significant direct effect on breastfeeding duration. This may be because the sample consisted of working mothers who struggled with several barriers during the breastfeeding journey. Barriers included social, psychological, environmental, and practical problems in performing EBF after returning to work [75]. Although the mothers in this study performed breastfeeding initiation, many failed to maintain exclusive breastfeeding up to the age of 6 months because the majority of them only had 2 months' maternity leave before going back to work full time. A previous study found that while almost all working mothers in Ghana initiate breastfeeding within the 1st hour of delivery, only $10.3 \%$ breastfeed exclusively up to the age of 6 months [76]. A short maternity leave and full-time work status influences exclusive breastfeeding duration among working mothers even when they have high intentions to breastfeed exclusively [77]. 
http://wjst.wu.ac.th

\section{Strengths and limitations}

There were several strengths of this study. Well-known human behavior theory and 5 other concepts were used that were well-developed and tested across countries. The research instruments had high validity and reliability. An adequately large sample size was recruited using multistage random sampling and the data were analyzed using path analysis. Equal numbers of mothers regarding parity and infant genders were recruited. The limitation of this study was that the data were collected between 6 and 12 months after delivery. The respondents might have forgotten the correct answers to some of the questions. Thus, the study findings cannot be generalized for mothers with different characteristics and other groups of lactating mothers.

\section{Conclusions}

The results of this study support the theory of planned behavior and partially support the findings of previous studies. The results may be used as a base to develop a comprehensive intervention program to prolong breastfeeding duration, especially among working Muslim mothers. Health care providers should take into consideration mothers' attitudes toward breastfeeding, their breastfeeding knowledge, and intention to breastfeed as these have a high predicted value of breastfeeding duration among working mothers.

\section{Acknowledgments}

This study would not have been possible without funding from the Indonesian Directorate General of Higher Education; Faculty of Nursing, Prince of Songkla University; and Jenderal Soedirman University.

\section{References}

[1] S Verick. Female labor force participation in developing countries. IZA World Labor 2014; 2014, 1 10.

[2] S Indonesia. Angka partisipasi kerja di Provinsi Jawa Tengah Tahun 2012, Available at: https:// jateng.bps.go.id/statictable/2017/03/22/1476/penduduk-jawa-tengah-berumur-15-tahun-ke-atasmenurut-jenis-kegiatan-seminggu-yang-lalu-dan-jenis-kelamin-di-provinsi-jawa-tengah-20072017.html, accessed May 2017.

[3] F Shuhaimi and N D Muniandy. The association of maternal employment status on nutritional status among children in selected kindergartens in Selangor, Malaysia. Asian J. Clin. Nutr. 2012; 4, 53-66.

[4] KL Tan. Factors associated with non-exclusive breastfeeding among 4-week post-partum mothers in Klang District, Peninsular Malaysia. Malays J. Nutr. 2009; 15, 11-8.

[5] WHO. Breastfeeding, Available at: https://www.who.int/nutrition/topics/exclusive_breastfeeding/ en, accessed June 2017.

[6] S Indonesia. Survey demografi dan kesehatan Indonesia Tahun 2012, Available at: http://kesga. kemkes.go.id/images/pedoman/SDKI\%202012-Indonesia.pdf, accessed May 2017.

[7] IM of Health. Indonesian health profile 2012, Available at: http://www.depkes.go.id/resources/ download/pusdatin/profil-kesehatan-indonesia/profil-kesehatan-indonesia-2012.pdf, accessed July 2017.

[8] S Bayyenat, G Hashemi, S Amirhosein, A Purbaferani, M Saeidi and G H Khodaee. The importance of breastfeeding in Holy Quran. Int. J. Pediatr. 2014; 2, 339-47.

[9] DA Inayati, V Scherbaum, RC Purwestri, E Hormann, NN Wirawan, J Suryantan, S Hartono, MA Bloem, RV Pangaribuan and HK Biesalski. Infant feeding practices among mildly wasted children: A retrospective study on Nias Island, Indonesia. Int. Breastfeed. J. 2012; 7, 1-9.

[10] F Zaidi. Challenges and practices in infant feeding in Islam. Br. J. Midwifery. 2014; 22, 167-72.

[11] MD Anggraeni, B Aji, R Setiyani, A Kartikasari and E Rahmawati. How do modern parents deal with cultural beliefs about breastfeeding? A qualitative study. Br. J. Midwifery 2018; 26, 605-13.

[12] RM Amin, ZM Said, R Sutan, SA Shah, A Darus and K Shamsuddin. Work related determinants of 
http://wjst.wu.ac.th

breastfeeding discontinuation among employed mothers in Malaysia. Int. Breastfeed. J. 2011; 6, 16.

[13] RL Biswas. 2011. Family support on exclusive breastfeeding practice among mothers in Bangladesh, MNS. Thesis. Prince of Songkla University, Hatyai, Thailand.

[14] S Khatun. 2010. The influence of breastfeeding attitude and subjective norm on intention to exclusive breastfeeding of mothers in Dhaka, Bangladesh, MNS. Thesis. Prince of Songkla University, Hatyai, Thailand.

[15] A Wicitra. 2009. Pengaruh pengetahuan dan dukungan keluarga terhadap pemberian ASI eksklusif pada ibu pekerja swasta di Jakarta, BNS. Thesis. Universitas Indonesia, Depok, Indonesia.

[16] D Lestari, R Zuraida and TA Larasati. Hubungan tingkat pengetahuan ibu tentang air susu ibu dan pekerjaan ibu dengan pemberian ASI eksklusif di Kelurahan Fajar Bulan. J. Major 2013; 2, 88-99.

[17] Y Bai, CYJ Peng and AD Fly. Validation of a short questionnaire to assess mothers' perception of workplace breastfeeding support. J. Acad. Nutr. Diet. 2008; 108, 1221-5.

[18] MMEA Ghwass and D Ahmed. Prevalence and predictors of 6-month exclusive breastfeeding in a rural area in Egypt. Breastfeed. Med. 2011; 6, 191-6.

[19] PD Hill and SS Humenick. Insufficient milk supply. Image J. Nurs. Scholarsh. 1989; 21, 145-8.

[20] E DiFrisco, KE Goodman, WC Budin, MW Lilienthal, A Kleinman and B Holmes. Factors associated with exclusive breastfeeding 2 to 4 weeks following discharge from a large, urban, academic medical center striving for baby-friendly designation. J. Perinat. Educ. 2011; 20, 28-35.

[21] KA Hidayat and J Dewantiningrum. Perbandingan pelaksanaan inisiasi menyusu dini berdasarkan tingkat pengetahuan ibu hamil. J. Ked. Diponegoro. 2012; 1, 1-13.

[22] NA Al-Akour, MY Khassawneh, YS Khader, AA Ababneh and AM Haddad. Factors affecting intention to breastfeed among Syrian and Jordanian mothers: A comparative cross-sectional study. Int. Breastfeed. J. 2010; 5, 6.

[23] T Mamonto. Faktor-faktor yang berhubungan dengan pemberian ASI eksklusif pada bayi di wilayah kerja Puskesmas Kotobangon Kecamatan Kotamobagu Timur Kota Kotamobagu. J. Kesmas 2015; 4, 56-66.

[24] LL Foo, SJS Quek, SA Ng, MT Lim and M Deurenberg-Yap. Breastfeeding prevalence and practices among Singaporean Chinese, Malay, and Indian mothers. Health Promot. Int. 2005; 20, 229-37.

[25] SO Lee. A study about breastfeeding knowledge, attitude and problem of breastfeeding in early postpartum period and breastfeeding practice. Korean J. Women Heal. Nurs. 2003; 9, 179-88.

[26] AD Camurdan, MN Ilhan, U Beyazova, F Sahin, N Vatandas and S Eminoglu. How to achieve long-term breast-feeding: Factors associated with early discontinuation. Public Health Nutr. 2008; 11, 1173-9.

[27] Y Afiyanti and D Juliastuti. Exclusive breastfeeding practice in Indonesia. Br. J. Midwifery. 2012; 20, 484-92.

[28] BH Munro. Statistical Methods for Health Care Research. $5^{\text {th }}$ ed. Philadelphia, Lippincott Williams \& Wilkins, 2013, p. 379.

[29] A Hilton and M Skrutkowski. Translating instruments into other languages: Development and testing processes. Cancer Nurs. 2002; 25, 1-7.

[30] TAT Ismail and Z Sulaiman. Reliability and validity of a malay-version questionnaire assessing knowledge of breastfeeding. Malaysian J. Med. Sci. 2010; 17, 32-9.

[31] J S House. Work Stress and Social Support. London, Addison-Wesley, 1981.

[32] KA Wambach. Breastfeeding intention and outcome: A test of the theory of planned behavior. Res. Nurs. Heal. 1997; 20, 51-9.

[33] PD Hill and SS Humenick. Development of the H \& H lactation scale. Nurs. Res. 1996; 45, 136-40.

[34] B Punthmatharith and J Singh. A psychometric assessment of the H \& H lactation scale in a sample of Thai mothers using a repeated measurement design. Nurs. Res. 2005; 54, 313-23.

[35] I Ajzen. The theory of planned behavior. Orgniz. Behav. Hum. Decis. Process. 1991; 50, 179-211.

[36] World Health Organization. Breastfeeding, Available at: https://www.who.int/nutrition/topics/ exclusive_breastfeeding/en, accessed July 2017. 
http://wjst.wu.ac.th

[37] SE Kotan. 2007, Predictors of breastfeeding intention among low-income women, MNS. Thesis. The Florida State University, Florida, USA.

[38] LA Rempel, JK Rempel and KCJ Moore. Relationships between types of father breastfeeding support and breastfeeding outcomes. Matern. Child Nutr. 2017; 13, 1-14.

[39] L Duckett, S Henly, M Avery, S Potter, S Hills-Bonczyk, R Hulden and K Savik. A theory of planned behavior-based structural model for breast-feeding. Nurs. Res. 1998; 47, 325-36.

[40] JE Dodgson, M Tarrant, DY T Fong, X Peng and WC Hui. Breastfeeding patterns of primiparous mothers in Hong Kong. Birth 2003; 30, 195-202.

[41] TH Hashim, M Mgongo, J Katanga, JG Uriyo, DJ Damian, B Stray-Pedersen, M Wandel and SE Msuya. Predictors of appropriate breastfeeding knowledge among pregnant women in Moshi Urban, Tanzania: A cross-sectional study. Int. Breastfeed. J. 2016; 12, 1-8.

[42] LD Carter and F Ukoli. Comparing the breastfeeding patterns of nulliparous and multiparous African-American women. Obstet. Gynecol. 2016; 127, 19-20.

[43] D Behera and KA Kumar. Predictors of exclusive breastfeeding intention among rural pregnant women in India: A study using theory of planned behaviour. Rural Remote Heath 2015; 15, 1-10.

[44] EH Emmott and R Mace. Practical support from fathers and grandmothers is associated with lower levels of breastfeeding in the UK Millennium Cohort study. PloS One 2015; 10, 1-8.

[45] N Novianti and M Mujiati. Faktor pendukung keberhasilan praktik inisiasi menyusu dini di RS swasta dan rumah sakit pemerintah di Jakarta. J. Kesehat. Reproduksi. 2015; 6, 31-44.

[46] N Cholifah and D Astuti. Hubungan antara sikap tenaga penolong persalinan, pengetahuan ibu dan dukungan keluarga dengan keberhasilan inisiasi menyusui dini. J. Ilmu Keperawatan Dan Kebidanan 2017; 8, 35-40.

[47] DK Nugraheni. 2011. Pengetahuan dan pelaksanaan inisiasi menyusui dini, pemberian ASI eksklusif serta status gizi Batita di perdesaan dan perkotaan. Thesis. Institut Pertanian Bogor, Bogor, Indonesia.

[48] BP Nastiti. 2012, Faktor-faktor yang berhubungan dengan praktek inisiasi menyusu dini di wilayah kerja Puskesmas Pangkah Kabupaten Tegal. Thesis, Universitas Negeri Semarang, Semarang, Indonesia.

[49] C Kamoun and D Spatz. Influence of Islamic traditions on breastfeeding beliefs and practices among African American Muslims in West Philadelphia: A mixed-methods study. J. Hum. Lact. 2018; 34, 164-75.

[50] P Vijayalakshmi, T Susheela and D Mythili. Knowledge, attitudes, and breast feeding practices of postnatal mothers: A cross sectional survey. Int. J. Health Sci. 2015; 9, 364-73.

[51] S Meedya, K Fahy and A Kable. Factors that positively influence breastfeeding duration to 6 months: A literature review. Women Birth 2010; 23, 135-45.

[52] CG Perrine, KS Scanlon, R Li, E Odom and LM Grummer-Strawn. Baby-friendly hospital practices and meeting exclusive breastfeeding intention. Pediatrics 2012; 130, 54-60.

[53] N Ratananugool. 2001, Factors influencing breast-feeding behavior among Thai adolescent mothers: A nursing predictive model, DNS. Thesis. University of Texas, Texas, USA.

[54] K Wijayanti, S Prawitasari and WA Nisman. Pengalaman ibu bekerja dalam pemberian ASI eksklusif di lingkungan Universitas Muhammadiyah Magelang. J. Kesh. Reprod. 2016; 3, 41-9.

[55] J Danso. Examining the practice of exclusive breastfeeding among professional working mothers in Kumasi metropolis of Ghana. Int J Nurs. 2014; 1, 11-24.

[56] SAA Hirani and R Karmaliani. Evidence based workplace interventions to promote breastfeeding practices among Pakistani working mothers. Women Birth 2013; 26, 10-6.

[57] DL Bai, DYT Fong and M Tarrant. Factors associated with breastfeeding duration and exclusivity in mothers returning to paid employment postpartum. Matern. Child Health J. 2015; 19, 990-9.

[58] M Bonet, L Marchand, M Kaminski, A Fohran, A Betoko, MA Charles and B Blondel. Breastfeeding duration, social and occupational characteristics of mothers in the French 'EDEN mother-child'cohort. Matern. Child Health J. 2013; 17, 714-22.

[59] TI Tsai, SH Huang and SYD Lee. Maternal and hospital factors associated with first-time mothers' breastfeeding practice: A prospective study. Breastfeed. Med. 2015; 10, 334-40. 
http://wjst.wu.ac.th

[60] KMR Burks. 2015, Mothers' perceptions of workplace breastfeeding support, MNS. Thesis, University of Vermont, Burlington, USA.

[61] M Dashti, JA Scott, CA Edwards and M Al-Sughayer. Predictors of breastfeeding duration among women in Kuwait: Results of a prospective cohort study. Nutrients 2014; 6, 711-28.

[62] KM Manhire, SM Williams, D Tipene-Leach, SA Baddock, S Abel, A Tangiora, R Jones and BJ Taylor. Predictors of breastfeeding duration in a predominantly Māori population in New Zealand. BMC Pediatr. 2018; 18, 1-10.

[63] RL Bergmann, KE Bergmann, KV Weizsäcker, M Berns, W Henrich and JW Dudenhausen. Breastfeeding is natural but not always easy: Intervention for common medical problems of breastfeeding mothers-a review of the scientific evidence. J. Perinat. Med. 2014; 42, 9-18.

[64] ED Jager, J Broadbent, M Fuller-Tyszkiewicz and H Skouteris. The role of psychosocial factors in exclusive breastfeeding to 6 months postpartum. Midwifery 2014; 30, 657-66.

[65] C Gatrell. Boundary creatures? Employed, breastfeeding mothers and 'abjection as practice'. Organ. Stud. 2017; 22, 1-22.

[66] VJ Flaherman, KG Hicks, J Huynh, MD Cabana and KA Lee. Positive and negative experiences of breast pumping during the first 6 months. Matern. Child Nutr. 2016; 12, 291-8.

[67] V Smith. Treatments for breast engorgement during lactation. Pract. Midwife 2014; 17, 42-4.

[68] OO Balogun, A Dagvadorj, KM Anigo, E Ota and S Sasaki. Factors influencing breastfeeding exclusivity during the first 6 months of life in developing countries: A quantitative and qualitative systematic review. Matern. Child Nutr. 2015; 11, 433-51.

[69] EJ O’Sullivan, CG Perrine and KM Rasmussen. Early breastfeeding problems mediate the negative association between maternal obesity and exclusive breastfeeding at 1 and 2 months postpartum. $J$. Nutr. 2015; 145, 2369-78.

[70] JC Kent, DK Prime and CP Garbin. Principles for maintaining or increasing breast milk production. J. Obstet. Gynecol. Neonatal Nurs. 2012; 14, 114-21.

[71] RJ McInnes, A Arbuckle and P Hoddinott. How UK internet websites portray breast milk expression and breast pumps: A qualitative study of content. BMC Pregnancy Childbirth 2015; 15, 1-11.

[72] A Motee, D Ramasawmy, P Pugo-Gunsam and R Jeewon. An assessment of the breastfeeding practices and infant feeding pattern among mothers in mauritius. J. Nutr. Metab. 2013; 2, 1-8.

[73] H Kronborg, I Harder and EOC Hall. First time mothers' experiences of breastfeeding their newborn. Sex. Reprod. Healthc. 2015; 6, 82-7.

[74] JM Wojcicki, R Gugig, C Tran, S Kathiravan, K Holbrook and MB Heyman. Early exclusive breastfeeding and maternal attitudes towards infant feeding in a population of new mothers in San Francisco, California. Breastfeed. Med. 2010; 5, 9-15.

[75] B Stewart-Knox, K Gardiner and M Wright. What is the problem with breast-feeding? A qualitative analysis of infant feeding perceptions. J. Hum. Nutr. Diet. 2003; 16, $265-73$.

[76] EJ Dun-Dery and AK Laar. Exclusive breastfeeding among city-dwelling professional working mothers in Ghana. Int. Breastfeed. J. 2016; 11, 1-9.

[77] KR Mirkovic, CG Perrine and KS Scanlon. Paid maternity leave and breastfeeding outcomes. Birth 2016; 43, 233-9. 